\title{
A Comparison of Traditional Ultrasound and Sustained Acoustic Medicine (SAM)
}

\author{
David 0 Draper* \\ Professor of Athletic Training/ Sports Medicine, Brigham Young University, USA
}

*Corresponding author: David O Draper, Professor of Athletic Training/ Sports Medicine, Brigham Young University, USA

\section{Introduction}

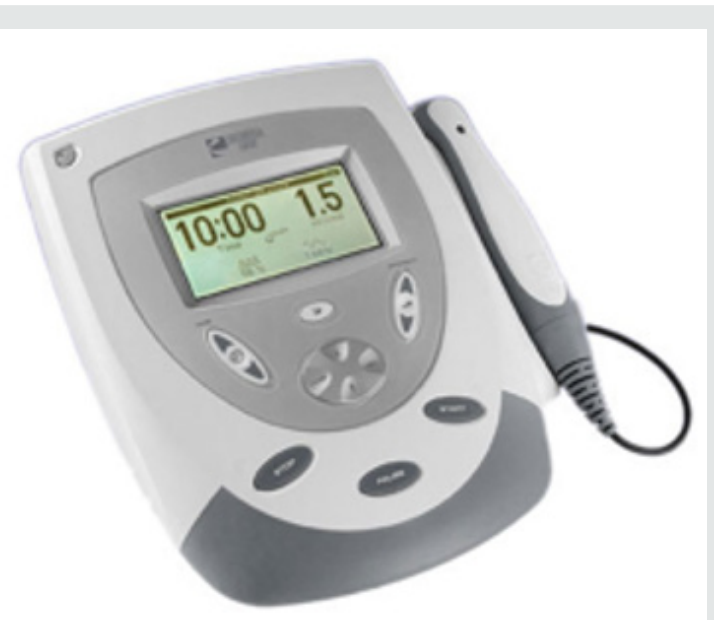

Figure 1: Traditional Ultrasound.

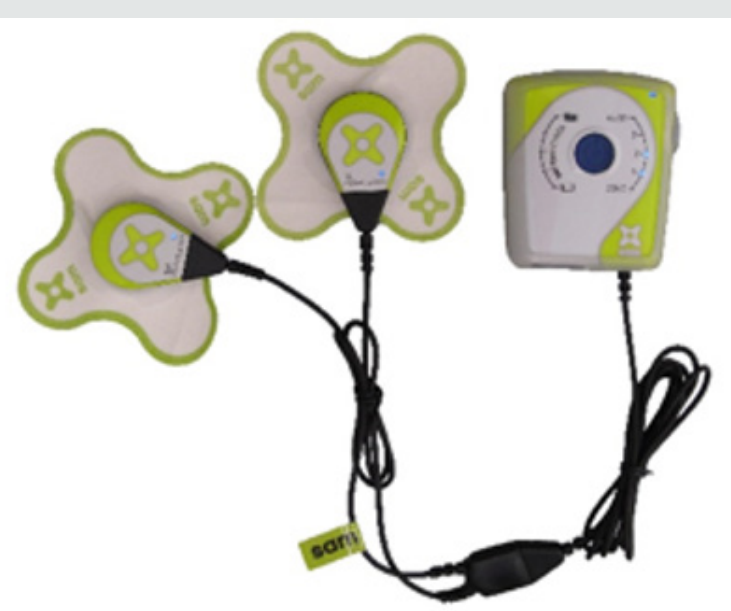

Figure 2: Sustained Acoustic Medicine (SAM).
Shortly after world war II therapeutic ultrasound was developed to treat musculoskeletal injuries (Figure 1). In 2008 doctoral student George Lewis gets literally "shocked" at the Cornel Lab. Shortly after that he invents and patents, a low voltage, low impedance, portable, wearable, rechargeable ultrasound device. At a meeting of doctoral students at Cornel where students would present their doctoral studies Lewis said, his ultrasound device would "change the world". Thus, Sustained Acoustic Medicine (SAM) Figure 2 was released to the public. Today, 2019 the device is used by several universities, hockey, basketball, football and baseball professional sports teams, and by US government healthcare agencies.

\section{Research on SAM}

a. There have been several research studies on SAM. It has been found to:

b. Increase human muscle temperature $54 \mathrm{C}$ at $1.5 \mathrm{~cm}$ deep and $3-4 \mathrm{C}$ at $3 \mathrm{~cm}$ deep.

c. It has been found to decrease pain in subjects with tendinopathy, all symptoms of inflammation, and even assisted in bone growth.

d. It has been found to restore lost muscle function in subjects, and improve grip strength.

e. It has been shown to significantly improve joint function and reduce pain of patients with knee osteoarthritis in multiple placebo-controlled studies.

f. In 2014 the SAM was tested in subjects with chronic trapezius pain. This was a double-blind study performed on 33 
patients. The office that makes SAM recorded the serial number on each device. They then shipped 33 devices to my lab at Brigham Young University. Each device was numbered before it shipped. Each device and randomly assigned to each subject.
Thus 8 students received the sham and 25 subjects received the actual treatment. The active treatment group decreased pain significantly better than the sham group $(\mathrm{p}<0.001)$.

\section{Comparison of Traditional Therapeutic Ultrasound with SAM:}

\section{Traditional}

- Has both 1 and 3MHZ settings

- Has thermal effects of $4-5^{\circ} \mathrm{C}$ at $5 \mathrm{~cm}$ deep

- Is large, about the size of a 3 ring binder

- Not portable, have to plug in to an outlet

- Not portable (cont.) cannot be used during activity

- Soundhead must be moved at a rate of $4 \mathrm{~cm} / \mathrm{sec}$

- Has only 1 crystal working at a time

- Crystal treats 2-3 times the size of the transducer

- In Joules delivers between 2,500-5,000 = less power stronger

- Because the transducer is moving, gel is messier

- Reduces pain in muscle/tendon

- Effective in tissue healing

- Typical treatment is $8-15 \mathrm{~min}$

- Typical treatment is $2-3 \mathrm{~W} / \mathrm{cm}^{2}$

\section{Conclusion}

As can be seen, the SAM has many advantages over typical ultrasound, including being small and portable. Physical and

\section{$\underline{\text { SAM }}$}

- Currently has only $3 \mathrm{MHz}$

- Has thermal effects at $1.5 \mathrm{~cm}$ to $3 \mathrm{~cm}$ deep

- Is small, about the size of a cell phone

- Portable, operated with a re-chargeable battery

- Portable (cont.) can use during activity

- Stationary crystals don't need to be moved

- Can have 2 crystals working at a time

- 2 crystals can treat baseball sized area

- Delivers between 9,000 and 18,000 Joules = stronger

- Static transducer = no messy gel

- Reduces pain in muscle/tendon

- Effective in tissue healing including bone

- Can treat for 1,2 and 4 hours

- Treatment is $0.132 \mathrm{~W} / \mathrm{cm}^{2}$

occupational therapists and athletic trainer should consider using it for their patients.

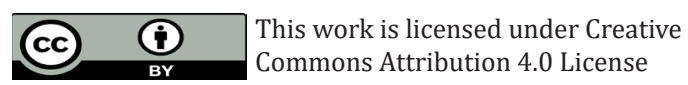

To Submit Your Article Click Here: Submit Article

DOI: $10.32474 /$ OSMOAJ.2019.02.000148

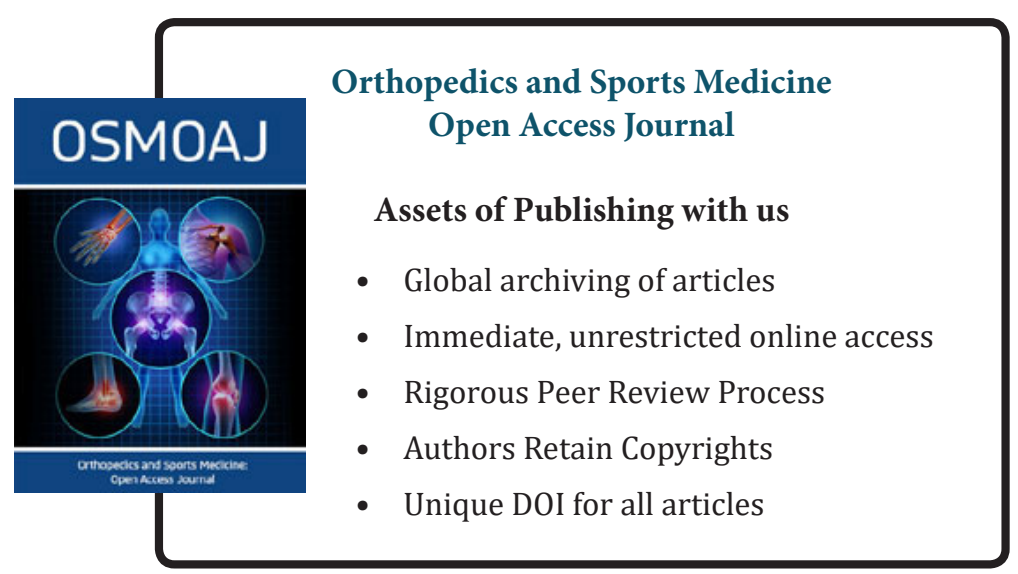

